\title{
Title: Exploring the Role of Innovativeness and Opinion Leadership in Diffusion
}

\begin{abstract}
:
Despite the extensive studies in the field of diffusion, the role of innovativeness in diffusion models has not reached a consensus and the literature has dedicated little effort to modelling customers' heterogeneous opinion leadership. These gaps could be some of the key limits for the further exploration of the diffusion phenomena. This study proposes that the use of innovativeness in diffusion models can be seen as a filter for potential customers and as an indicator for customers' opinion leadership. We analyse the respective roles of innovativeness and opinion leadership in diffusion based on the suggested model. We also show the model's potential to identify and predict the opinion leaders of a diffusion system. We implement the proposed model in the case of a 36 mobile phone technology. The results demonstrate good fitting and forecasting performance of the model. We hope the insights offered by this study can benefit both innovation academics and practitioners.
\end{abstract}

Key words: Diffusion; Opinion Leadership; Innovativeness 


\section{INTRODUCTION}

Innovations have been recognized as key drivers for firms' profitability (Hamilton, 1982; Hauser et al., 2006) and thus are vital for firms' survival (Crespell et al., 2006). Diffusion, together with creation and commercialisation, are considered as the three pillars in the successful introduction of an innovation. It is argued that innovation has little social or economic impact without diffusion (Hall, 2005), as it is commonly observed that for most innovations it takes a long time for the extent of ultimate use to be attained. A typical example is the use of communication tools, such as mobile phones, in which case the tools can achieve their optimum performance only when the majority of people have adopted these products. Also for firms, to understand diffusion is also to understand the market growth of their new products. Therefore, to explain and predict the diffusion trend in an accurate manner is essential for firms' marketing and production strategies (Amini and Li, 2011; Amini et al., 2012).

Innovativeness and opinion leaders are two of the hottest areas of discussion in diffusion, as their concepts cover two types of diffusion drivers respectively: the former explains the level of customers' propensity to adopt innovations (Klink and Athaide, 2010) and the latter studies the customers who have higher influence in the system (lyengar et al., 2011). Although there are extensive studies of innovativeness and opinion leadership in the existing literature, the two topics are still under debate and offer potential opportunities for further research and applications. Especially in the field of diffusion models, for instance, the way in which innovativeness should be utilised to model diffusion has not reached a consensus (Hauser et al., 2006); the consideration of opinion leadership in diffusion models is mostly studied on a homogeneous level such as the Bass model (Bass, 1969) or a partially heterogeneous level (Van den Bulte and Joshi, 2007), while little is known from an entirely heterogeneous point of view; also we realise that the existing literature does not show an applicable approach for assessing and quantifying individual customers' opinion leadership in a vast system, nor a valid way of modelling it. We argue that these gaps are some of the key limits for the further understanding of the diffusion phenomena. 
This study proposes a model of the diffusion process considering individual customers' innovativeness and opinion leadership. This study is important for two main reasons: first, because academics increasingly desire to know the roles of various diffusion drivers and, second, because practitioners constantly demand a better explanation tool of diffusion to aid their strategic decisions. The results of the study are of both theoretical and managerial interest, from the following perspectives. First, due to different firm strategies at different stages, innovations may target different customers through time. Usually, innovations target highly innovative customers initially and then gradually expand to cover the majorities. Hence, we use customer innovativeness as a threshold to filter potential adopters at different stage of diffusion and target a good fit in the empirical study. Second, according to our current knowledge, our model is one of the few of its type that have an applicable way to model individual customer's opinion leadership. We show our model's the potential to identify and predict the opinion leaders of a diffusion system. Also the model can help explore how the heterogeneity of customers' opinion leadership in a system will influence diffusion. Third, the diffusion models that consider customers' adoption behaviour from an individual level are limited by computing power when applied to a large-scale system. By introducing a parameter that controls the level of model heterogeneity, the proposed model is capable to explain large-scale cases. Finally, the proposed model exhibits good performance in explaining and forecasting diffusion phenomena, therefore, is capable to better aid firms' marketing and production strategies.

The remainder of this study is structured as following. In Section 2, we conduct a review of the related literature. Section 3 explains the proposed model. Then, we implement the proposed model in Section 4 in order to explain the diffusion case of a Japanese 3G mobile phone technology and compare its performance with the Bass model and the G/SG model. Section 5 presents some further discussions based on the model. Finally, conclusions are drawn and some future directions are suggested. 


\section{RELATED LITERATURE}

\subsection{Diffusion Models}

It is well known that the resulting curve of a typical diffusion process is usually a bell-shaped curve, where the number of innovation adopters is plotted versus time (Griliches, 1957). Following this observation, a number of models have been proposed, some of them originating from the desire to provide a means to understand the phenomena better, others simply driven from the desire to fit the real world data. Diffusion models are either homogeneous or heterogeneous in nature. These two streams of models can both illustrate the bell-shaped curve of diffusion with meaningful implications. Both, are therefore widely used (Geroski, 2000).

Most homogeneous diffusion models originate from the two-step flow theory (Katz and Lazarsfeld, 1955), which states that information of an innovation will first reach a few individuals through the mass media and then spread to others through the word-of-mouth effect. The pioneering work in this field is mostly credited to the Bass model (1969): if $f_{t}$ is defined as the percentage of potential adopters who adopt the product at time $\mathrm{t}$ and $F_{t-1}$ is the penetration rate, the discrete analogue of the product diffusion process can be written in the form of Equation 1, where $p$ and $q$ are the parameters of two key diffusion drivers: $a$ constant diffusion driver that can be explained by the mass media effect or customers' inner intention to adopt, and a dynamic drivers this is dependent on the number of other adopters (i.g. word-o-mouth effect, network effect).. The Bass model has influenced many of the subsequent diffusion studies, as summarised by Geroski (2000), Mahajan et al. (2000), and Peres et al. (2010).

$$
f_{t}=\left(p+q F_{t-1}\right)\left(1-F_{t-1}\right)
$$

Conversely, heterogeneous diffusion models consider the differences of adoption timing between individuals, which take place due to their respective goals, needs, and abilities. In other words, the reason why a diffusion process is formed is because customers adopt the innovation at different time when their requirements for adoption are satisfied. Compared with homogeneous diffusion models, the heterogeneous models emphasise the heteroge- 
neity of individual characteristics regarding innovation adoption. For instance, based on the assumption that firm size represents the firms' capability of adopting innovation, Davies (1979) uses firm size as input to predict firms' innovation adoption behaviour and consequently model the diffusion curve. One of the more recent developments in the field of heterogeneous diffusion models can be seen in the agent based diffusion models, where each customer is considered as an agent that exhibits unique characteristics and makes adoption decisions following their own rules (Di Benedetto, 2011; Rand and Rust, 2011). For instance, Emmanouilides and Davies (2007) model the interactions between individual agents in new product diffusion process. van Eck et al. (2011) explore the role of opinion leaders in diffusion through an agent-based modelling approach, and Amini et al. (2012) propose an agentbased model to analyse the production-sales policies on the diffusion of a new generic product.

\subsection{Innovativeness and Opinion Leadership}

Customers' attitudes toward innovations are naturally distinct from one another. Reflecting on the above, scholars use the term innovativeness to define the consumers' propensity to adopt innovations (Hauser et al., 2006; Klink and Athaide, 2010). A variety of innovativeness measures have been developed in the existing literature. For instance, innovativeness can be quantified by customers' past and current innovation performance (Midgley and Dowling, 1978; Wolfe, 1994); innovativeness can be identified through surveys or interviews with scaled questions(Roehrich, 2004; Wang and Ahmed, 2004); innovativeness can also be explained by certain indicators: on the firm level, these indicators could be firm size or R\&D investment (Smith, 2005); on the individual level, these indicators could be personal income (Van den Bulte and Stremersch, 2004).

Furthermore, customers are also distinct in terms of their influential power in the system. The term 'opinion leader' is defined as an individual who leads in influencing others' opinions (Lazarsfeld et al., 1940). Hence, customers who have higher opinion leadership tend to influence more others' adoption decisions. Opinion leadership is usually viewed as a monomorphic, case-specific measure of individual differences; that is, a customer that has higher opinion leadership in one diffusion process may be a follower in another (Tellis et al., 2009). Measures of opinion leadership are also diverse. The early attempt of assessing customers' 
opinion leadership can be traced back to the work of Rogers and Cartano (1962). As summarised by Weimann et al. (2007), Rogers (2003), and lyengar et al. (2011), the existing ways of determining opinion leaders such as the positional, reputational, self-designating, and sociometric approaches, as well as observation and the key informant approach, are normally achieved through observations and surveys.

In this study, we emphasize two perspectives of the relationship between innovativeness and opinion leadership. First, although they are different concepts in nature, innovativeness and opinion leadership share many attributes (Rogers, 2003; Tellis et al., 2009). Therefore, it is easy to deduce a positive relationship between innovativeness and opinion leadership from their definitions alone, since an opinion leader will only adopt an innovation earlier before it can be passed on to others (van Eck et al., 2011). This positive relationship has been proven by several empirical studies (Flynn et al., 1996; Goldsmith and Hofacker, 1991; Ruvio and Shoham, 2007; Summers, 1971). A study conducted by Midgley and Dowling (1993) even uses opinion leadership as a measure for innovative predisposition. Second, it is those innovative, but not the most innovative, customers, who possess the highest opinion leadership in the system (Rogers, 2003). This is because the most innovative customers usually desire different attributes from the innovations than the majority, and therefore their adoption decision may not influence many others. This concept has been widely accepted in the existing literature, especially in the high technology industries to study the market chasm (Moore, 1991) and the saddle effect in diffusion (Goldenberg et al., 2006; Goldenberg et al., 2002; Muller and Yogev, 2006; Peres et al., 2010). To sum up, we propose that customers' opinion leadership will initially increase with its increased innovativeness and then decrease after innovativeness reaches a certain point.

\subsection{Innovativeness and Opinion Leadership in Diffusion Models}

Customers with higher innovativeness are likely to adopt innovations earlier. Innovativeness is perhaps one of the closest concepts to diffusion, as it directly influences customers' adoption behaviour and, consequently, the diffusion process of the system. In the simplest case, if innovativeness can accurately predict each customer's adoption timing, the corresponding diffusion curve can be drawn directly (Rogers, 2003). In a more complicated case (the G/SG model), a customer's adoption probability through time follows a shifted Gompertz distribu- 
tion with parameters $b$ and $\eta$, in which $\eta$ represents the consumer's tendency to adopt late (reverse innovativeness) and follows a Gamma distribution (Bemmaor, 1994). Furthermore, innovativeness and its indicators are often used as a threshold to determine customers' adoption behaviour in diffusion models, such as in the studies of Davies (1979), Van den Bulte and Stremersch (2004), and van Eck et al. (2011).

Customers' opinion leadership in diffusion models was mostly considered on a homogeneous level in the early days. Recently, the focus of opinion leadership in diffusion models has been gradually moving into a heterogeneous level, as diffusion modellers have noticed the importance of differentiating customers based on their influential power in the system. For instance, some scholars (Goldenberg et al., 2009; Van den Bulte and Joshi, 2007; van Eck et al., 2011) have tried to use a simple typology to classify customers into influential ones and imitators, in order to explore their respective roles in diffusion. In this study, we seek to further this towards a more heterogeneous level.

Perhaps the present study is more akin to that of van Eck et al. (2011), which seeks to understand the role of opinion leaders in diffusion through an agent-based modelling approach. However, we see several limitations in their work, which can be improved in the current study. First, their model categorises customers into opinion leaders and non-opinion leaders based on a simulated network structure, thus, does not reveal the close link between opinion leadership and innovativeness. Second, their model uses innovativeness as a direct determiner of customers' adoption decision. To the contrary, a precise and applicable measurement of innovativeness to match customers' adoption behaviour is required, which is not provided. Finally, their model is not supported from a real word case, since the data required by the model are difficult to obtain.

\section{PROPOSED MODEL}

In the proposed model we group the studied customers of diffusion into a certain number of agents, so we let: (1) each agent in the studied system consists of $M_{\text {agent }}$ customers; (2) the customers in each agent are homogeneous in nature. In other words, we introduce a parameter $M_{\text {agent }}$ to control the heterogeneous level of the system: when the parameter value reduces to 1 , meaning only one customer in one agent, the proposed model will reduce to a 
typical agent-based model; when the parameter value increases and reaches the whole population of the system, all the customers are thought to have the same characteristics and the proposed model becomes a homogeneous diffusion model. By setting heterogeneity at an appropriate level, it is expected that the proposed model can be applied to cases with large-scale systems, produce deterministic results for the parameter estimation and curve-fitting, and at the same time offer enough level of heterogeneity for the analysis.

$$
\begin{gathered}
\text { Threshold }_{t}=\frac{\text { Threshold }_{t-1}}{1+\delta t} \\
P_{i, t}=p+q \times \sum_{j=1}^{M / M_{\text {agent }}}\left(\frac{F_{j, t-1}}{M_{\text {agent }}} O L_{j}\right) \text {, if } I_{i} \geq \text { Threshold }_{t} \\
P_{i, t}=0, \text { if } I_{i}<\text { Threshold }_{t} \\
s_{i, t}=P_{i, t}\left(M_{\text {agent }}-F_{i, t-1}\right) \\
F_{i, t}=\sum_{t^{\prime}=1}^{t} s_{i, t^{\prime}}
\end{gathered}
$$

It is assumed that an innovation diffuses in a market with $M$ customers, and thus there will be $M / M_{\text {agent }}$ agents in the system. We propose a threshold Threshold $_{t}$, which if crossed by a customer's innovativeness $I_{i}$ then the customer has the potential to consider adopting the innovation. We further assume that the threshold will decrease through time due to the innovation's decreased price relative to its utility (see Equation 2, where $\delta$ is a discount factor).

We propose a fully connected network for the network structure of the system; namely that any two customers in the system are able to communicate with each other regarding the innovation. As previously mentioned, the Bass model (1969) and most of its extensions consider two key drivers of diffusion: one is constant through time which can be explained as mass media effect or customers' inner intention to adopt, while the other is depended on 
the number of other adopters, thus is related to the word of mouth effect and network effect. Following this modelling concept we use Equation 3 to explain the probability of potential customers in agent i who adopt the innovation at time $\mathrm{t}\left(P_{i, t}\right)$, where $\mathrm{p}$ and $\mathrm{q}$ are the parameters of the two key diffusion drivers respectively, $F_{j, t}$ is the number of adopters in agent $\mathrm{j}$ at time $\mathrm{t}$, and $O L_{j}$ is the relative opinion leadership of the customers in agent $\mathrm{j}$. Note that in Equation 3 we only use $O L_{j}$ to explain the customers' relative opinion leadership within the system. The change of the overall level of opinion leadership will be reflected by the change of parameter $q$, in a manner equal to the Bass model. Consequently, the number of new adopters and the number of cumulative adopters in agent $\mathrm{i}$ at time $\mathrm{t}\left(s_{i, t}\right.$ and $\left.F_{i, t}\right)$ are explained by Equation 4 and Equation 5 .

$$
\Phi_{i}=\left\{\begin{array}{l}
\frac{e^{-\left(\frac{\bar{I}}{\text { Peak }} I_{i}-\bar{I}\right)^{2} / 2(\beta \sigma)^{2}}}{\sqrt{2 \pi} \beta \sigma}, I_{i}<\text { Peak } \\
\frac{e^{-\left(\frac{P e a k}{\bar{I}} I_{i}-\frac{P e a k^{2}}{\bar{I}}\right)^{2} / 2(\beta \sigma)^{2}}}{\sqrt{2 \pi} \beta \sigma}, I_{i} \geq \text { Peak }
\end{array}\right.
$$

$$
\text { Peak }=\bar{I}+\alpha \sigma
$$

Now we present our model of customers' opinion leadership. Based on the previous discussion, we assume that customers' opinion leadership follows a skewed bell-shaped curve if plotted against innovativeness: opinion leadership initially increases along with innovativeness and then decreases after innovativeness has reached a certain point. We introduce Equation 6 to plot the curve, where $I_{i}$ is the innovativeness of customers in agent i and $\Phi_{i}$ is the corresponding opinion leadership. Equation 6 is modified based on the normal distribution function with $\bar{I}$ and $\sigma$ being the mean and standard deviation of innovativeness of the system. The idea of this function is that we twist the normal distribution curve to a 
skewed bell-shaped curve by introducing two parameters. Specifically, as in Figure 1, we introduce parameter $\alpha$ to change the peak point of the normal distribution curve from $\bar{I}$ to Peak and introduce parameter $\beta$ to modify $\sigma$ in order to change the concentration level of the normal distribution curve (we define the value of Peak as in Equation 7, showing how much the changed peak point differs from the original peak point). Therefore, $\alpha$ and $\beta$ can be considered as the shape and scale parameters of the curve, respectively.

It should be noted that the produced curve of Equation 6 also can be right skewed, when the value of parameter $\alpha$ is negative. A right skewed curve here means less innovative customers are more influential within the system. It is likely to happen when the system is reluctant to adopt the change. However, we do not discuss this type of opinion leadership curve in this study, as this is not a usual case in diffusion. Figure 2 shows example curves produced by Equation 6 and Equation 7 with different shape and scale parameters. Finally, we use Equation 8 to normalise the value of $\Phi_{i}$ in order to get the relative opinion leadership of customers in agent $\mathrm{i}$ in the system $\left(O L_{i}\right)$.

INSERT FIGURE 1 HERE

INSERT FIGURE 2 HERE

\section{THE CASE OF 3G MOBILE PHONE SERVICE IN JAPAN}

In this section, we demonstrate an implementation of the proposed model to show its practical capacity in explaining real diffusion phenomena. The case presented here is the third generation of mobile telecommunication service in Japan. 


\subsection{G Mobile Phone Service in Japan}

Japan is an island nation in East Asia. The country is a major economic power in the world with a population that is estimated at around 127 million (CIA, 2012). Japan is one of the more economically developed countries in the world. Although growth rate has been slightly fluctuating, the Japanese per capita GDP reached 42,831 US dollars (f29304) in 2010, according to World Bank data (2010).

NTT DoCoMo Inc. is the dominant mobile phone operator in Japan with more than half of the Japanese cellular market share. The company's 36 mobile service, Freedom of Mobile Multimedia Access (FOMA), is the first commercialised one of its type in the world. This service product was launched in October 2001 and has been used ever since. We obtained monthly subscription data for NTT DoCoMo Inc.'s FOMA service between October 2001 and November 2011 (122 data points in total) in the Japanese market (DoCoMo, 2011). The number of the new FOMA service subscribers each month follows a bell-shaped curve in general, but with fluctuations that may be caused by certain factors such as the seasonal effects. It should be emphasised that the company introduced a trial period after FOMA was released. During this period, only some selected highly innovative customers could receive and use this service, such as professionals in the telecommunication industry. Following the trial period, the company released the service to the market and the service started to spread quickly.

\subsection{Innovativeness and Income}

The lack of a generalised and widely-accepted measure of innovativeness is still one of the main obstacle for innovation studies (Hauser et al., 2006). In this study, we use the data of income as the input of innovativeness for the model. Customers with higher income are more likely to afford new products. Therefore, the diffusion literature has identified a correlated relationship between customers' income and innovativeness since its early age (Medina and Michaels, 1994; Midgley and Dowling, 1978; Rogers, 1962). In addition, although the concepts of innovativeness and income are different, the literature shows that the former can be interpreted by the latter in diffusion models. For instance, net profits and revenue growth are used as indicators of innovativeness on the firm level (Rogers, 1998). 
Studies, such as that of Van den Bulte and Stremersch (2004), also use people's income instead of innovativeness as input in diffusion models for their analysis. Finally, we argue that the above assumption could be tested by the results of the model fit: if innovativeness and income has no link to each other, it would be difficult for the model to fit the observed data. If we assume that customers' income follows a Gamma distribution with parameters $\mathrm{k}$ and $\theta$, we can use Equation 9 and Equation 10 below to explain the relationship between $k, \theta$, average income, and the Gini coefficient $(g)$, where $\mathrm{B}(k, k+1)$ is the Beta function. Here, we use GDP per capita to indicate average income. This is appropriate, because the average income of a country is directly related to its GDP per capita; and because the shape parameter $k$ of the income distribution function is only determined by the Gini coefficient (see Equation 9) and the average income is only used to determine the mean of the distribution.

$$
\begin{gathered}
g=\frac{1}{4^{k} k \mathrm{~B}(k, k+1)} \\
\theta=\frac{\text { Income }_{\text {average }}}{k}
\end{gathered}
$$

We use the mean value of GDP/capita and Gini coefficient between 2001 and 2011 as input in Equations 8 and 9. The parameters of the corresponding Gamma distributions are calculated as 2.7909 and $1.2779 \mathrm{E}+4$ respectively. Figure 3 shows the generated income distribution of Japan based on the above discussion.

INSERT FIGURE 3 HERE

\subsection{Parameter Estimation Technique}

Generic Algorithm estimation (Venkatesan et al., 2004) is used in this study for parameter estimation. We consider that a global estimation tool should be more appropriate here than the non-global ones (such as non-linear least square estimation), as it is more likely to reach a global optimum when the number of estimated parameters is large and the estimated 
curve has many fluctuations. We estimate the parameters of the proposed model by mini-

mizing the function of $\sum_{t=T_{0}}^{T}(E(s(t))-s(t))^{2}$, where $s(t)$ is the actual subscription data of the innovation and $E(s(t))$ is the value estimated by the model.

The software MatLab is used to compute the GA estimation result. The population size of the estimation is set as 200 (200 sample solution vectors are generated in each iteration). We use the software default value for the crossover and mutation $(0.8$ and 0.25$)$. The stopping rule for estimation is as follows: terminate if there is no improvement (less than 1E-09) in the objective function for 100 consecutive generations. We run the GA estimation for the model 100 times repeatedly. The reported values in this study are the mean and the standard deviation of the 100 estimates obtained from the repeats. The standard error and $p$ value of each parameter can be calculated correspondingly based on the mean value and standard deviation from the results.

We set $M_{\text {agent }}=60000$. Considering the population of Japan, there would be more than 1000 agents in the system, which should offer sufficient heterogeneity to the case. As the product had a trial period when the market size was deliberately controlled by the company, we introduce one more parameter, $\eta$ (the percentage of customers who were excluded from the trial) in order to explain the size of the potential market during this trial period.

\subsection{Results of Curve Fitting}

Since our model is derived from the Bass model, we give the estimated results by the Bass model here as a benchmark. Additionally, compared with other classical diffusion models such as the exponential model (Fourt and Woodlock, 1960), the logistic model (Mansfield, 1961), and the Gompertz equation, the Bass model is the best for describing diffusion patterns, especially for IT innovations (Kim and Kim, 2004, 2007). We choose the G/SG (Bemmaor, 1994) model as another benchmark for two reasons. First, the G/SG model is developed based on the understanding of the role of innovativeness in diffusion, and thus, is comparable with the proposed model. Second, the G/SG model is reported to have higher performance than the Bass model in explaining some diffusion cases (Bemmaor and Lee, 2002). 
A graphical representation of the models' fit with the observed data of Japan 36 mobile phone subscription is shown in Figure 2. We provide four measures of descriptive performance in Table 1: sum of squared errors of prediction (SSE), mean absolute deviation (MAD), root mean square error (RMSE), and R square (R).

Insert Table 1 here

Insert Table 2 here

INSERT FIGURE 4 HERE

As one of the more influential models in the history of management science, the Bass model has demonstrated that it is a good fit for studying diffusion processes in numerous cases. As a highly simplified model, however, the Bass model usually only depicts general trends in a less accurate manner. As is the case with this study, the Bass model exhibits the lowest fitting performance among the three. In particular, the Bass model overestimates the diffusion speed in the initial stage, underestimates the level of the peak point that the observed curve can reach, and underestimates the diffusion speed in the final stage.

The G/SG model performs very well in explaining the case study, with a performance similar to the proposed model. The curve produced by the G/SG model almost coincides with the trend of the observed data, and the model's statistical fitting results are only slightly worse than our model. Apart from its excellent fitting performance, however, we find it difficult to derive any managerial implications from its results. According to the reported value of the G/SG model, it suggests that customers' late adoption intention (revers innovativeness) follows a Gamma Distribution with parameters $\alpha=38.2257$ and $\beta=0.3055$, which is too different from the actual income distribution of Japan. Perhaps the innovativeness in the G/SG model follows an unknown definition that cannot be simply indicated by income. Alterna- 
tively, the G/SG model can simply be used as a curve-fitting tool here. Therefore, we exclude the G/SG model from the discussions of managerial implications in the following paragraph.

The proposed model has the best performance among the three, both statistically and graphically. Specifically, the proposed model performs significantly better than the Bass model and slightly better than the G/SG model. All the reported parameter values here are statistically significant, which is evidence of the importance of their respectively represented roles in the diffusion process. For instance, the reported values of parameters $\alpha$ and $\beta$ suggest that opinion leadership is not equally distributed within the system. The model reports a very high value of parameter $\eta(0.9952)$, meaning that only $0.48 \%$ of the customers with the highest innovativeness were targeted by the company at the initial stage of diffusion. Also the reported value of parameter $\delta$ is 0.0679 , showing a clear trend of customers gradually moving into the market.

\subsection{Forecasting Performance}

We also compare the forecasting performance of the suggested model with that of the Bass model and the G/SG mode. The results are reported using mean squared error, which has been widely used in assessing prediction accuracy of diffusion models. Following the approach of Kim and Srivastava (2007) and Decker and Gnibba-Yukawa (2010), we divide the data into the calibration period and the forecasting period. Then based on the parameter values reported from the calibration period, we forecast the subscription numbers of the forecasting period. We first use 100 data points in the calibration period to forecast the subscription data of the most recent 22 data points, in order the see the models' forecasting performance in the final stage of the observed curve. Then we use 70 data points in the calibration period to forecast the subscription data of the most recent 52 data points, in order to test the models' predictive accuracy soon after the diffusion's peak point. Finally, we use 40 data points in the calibration period to forecast the subscription data of the last 92 data points, in order to see the modes' predictive accuracy before the diffusion's peak point. The results (see Table 3 ) show that the proposed model has better performance than the Bass model and the G/SG model in the first two cases, significantly. The performance of the proposed model, however, is slightly worse than the G/SG model in the last case when forecast- 
ing the market growth before the peak point. The Bass model has the lowest performance among the three models in all cases.

Insert Table 3 here

\section{DISCUSSIONS}

After validating the proposed model using the case of Japanese $3 \mathrm{G}$ mobile phone technology, we provide some further discussions based on the model, with specific focus on the roles of innovativeness and opinion leadership in diffusion.

\subsection{Innovativeness}

Many diffusion processes have a rather slow initial stage, and then at a certain point, suddenly take-off (Chandrasekaran and Tellis, 2008). This phenomenon can be hardly explained by a simple sum of the mass media and word-of-mouth effects as in the Bass model. Mahajan and Peterson (1978) notice that the customer base of an innovation should be dynamic; namely that the number of customers who have the adoption potential is changing through time for various reasons. For instance, both decreased price and increased utility are likely to drag more individuals into the potential adopters group. Firms' market strategies also may target or exclude specific individuals during different periods. Especially in the initial stage of the innovation, its targeted customers are usually not the whole population base, but only a few innovators, as the majority will wait for either increased utility or decreased price. Because of the above issues, some scholars even argue that the nature of diffusion should be the democracy of the innovation (Sheth and Sisodia, 1999). Therefore, we use innovativeness to filter potential customers in order to reflect the change of the innovation's real customer potential through time. As in the case with this study, the diffusion of the innovation has a trial period, during which only highly innovative customers are targeted. Diffusion models that do not filter potential customers during this period will surely overestimate the diffusion rate (see Figure 3 for the results produced by the Bass model). Furthermore, the proposed model reports a higher mass media effect $(p=0.0731)$ than that of 
the Bass model $(p=0.0014)$. This is because the Bass model desires a low mass media effect to explain the slow diffusion rate in the initial stage, which is actually caused by the company's marketing strategy of limiting the customer base. This shows that the neglects of the dynamics of the potential market may also cause misunderstandings of other factors of diffusion. Finally, the proposed model performs visibly better than the Bass model in the final stage of the diffusion. The curve produced by the Bass model is approaching its ultimate level of penetration and thus, it underestimates the real market potential. With the filter role of innovativeness, the proposed model suggests that the total customer potential has not been utilised yet, which implies that the diffusion is still capable to continue if the product's price and utility are improved to meet the requirements of low innovativeness customers.

Measures of opinion leadership in the literature are usually through assessing individuals, and therefore these measures are only applicable when the studied group is relatively small. Conversely, innovativeness is relatively easier to be quantified than opinion leadership is. Although the close relationship between innovativeness and opinion leadership has been repeatedly emphasized in the literature, we believe this relationship has not been fully utilised in diffusion model studies. Therefore, we propose the second use of innovativeness in the current model to be its indicative potential for opinion leadership, which is evidenced by the empirical study.

\subsection{Opinion Leadership}

For the case with this study, the reported values of parameters $\alpha$ and $\beta$ suggest that the influential power of customers is mostly held by a few opinion leaders. Furthermore, the model and its results suggest that the most influential customers (opinion leaders) in the system are the ones who are slightly more innovative than the majorities. As can be seen in Figure 4.2, if we list the 1132 agents in the system based on their innovativeness from low to high, the opinion leaders are the ones who rank about 750.

As mentioned in the literature review section, opinion leadership is a case-specific measure of individual difference, that is, the same customer may exhibit different influential power in different diffusion cases. Hence, it is very difficult to identify opinion leaders in the system before the diffusion finishes. Combining the models' ability of identifying opinion leaders 
and the model's forecasting ability, our suggested model has the potential to predict the opinion leaders of a diffusion system. This will greatly help firms, as they can target those valuable customers and make appropriate marketing strategies before their rivals.

In the following paragraph, we further investigate how the heterogeneity of opinion leadership influences diffusion based on the proposed model. We would like to see how the changes of the shape and the scale parameters in our suggested model, as well as the corresponding opinion leadership curves influence the diffusion process.

We maintain the parameter value of $\beta$ and change the parameter value of $\alpha$ from 0.2466 to 0 and 1, accordingly. From Figure 5, it can be seen that the change of parameter $\alpha$ results in a change of opinion leadership heterogeneity in the system as expected: the higher value of $\alpha$ indicates that opinion leaders tend to be more innovative. Also we observe two main trends regarding the resulting diffusion curves. First, the change of parameter $\alpha$ does not impact the initial stage of the diffusion process. The change of the diffusion curve is only visible after about 40 data intervals. This is because opinion leadership influences diffusion through influencing word-of-mouth between customers, which is only visible after the number of adopters has reached a critical mass. Second, diffusion tends to be faster when the curve of opinion leadership versus innovativeness is left skewed (innovative customers tend to have higher opinion leadership). This is because the innovative opinion leaders will adopt the innovations earlier, influence others for a longer time, and seed up the whole diffusion process from a long-term perspective. According to Banerjee (1992), if innovators are high status individuals who can lead others to imitate them, the diffusion process will take place particularly fast.

INSERT FIGURE 5 HERE

We then manipulate the value of parameter $\beta$ in the model and at the same time maintain the values of other parameters. The resulting opinion leadership curve and diffusion curve are shown in Figure 6 . We list two main findings here. First, the impact of parameter $\beta$ starts to be visible only after certain time intervals, which is similar with the case of the shape parameter $\alpha$. Second, the diffusion curve produced by the bigger value of $\beta$ has a slightly slow- 
er take-off, but it diffuses faster soon after and can reach a higher peak point. Therefore, the findings here suggest an imbalanced opinion leadership structure where only a few innovators that are particularly influential and others that are satisfied with the role of 'followers' can speed up the diffusion. Although in such a system, customers' innovationseeking behaviour is relatively weak overall (most customers will just wait to follow the opinion leaders), innovation do tends to diffuse faster from an overall view, as suggested by our model and results.

INSERT FIGURE 6 HERE

To sum up, from previous diffusion studies we know that innovations diffuse faster if the general level of the word-of-mouth effect is high. In this study, we further demonstrated that the heterogeneity of customers' opinion leadership also plays an important role in influencing the diffusion process.

\section{CONCLUSIONS}

Innovations have been recognized as key drivers for firms' profitability in today's fast changing environments. It is critical for a firm to understand, monitor, and forecast the diffusion of new technologies in order to possess a competitive advantage over its rivals. Therefore, innovativeness and opinion leadership as two key drivers for diffusion have become the hottest research topics in the current literature. However, the role of innovativeness in diffusion models has not reached a consensus and the existing literature has dedicated little effort to modelling customers' heterogeneous opinion leadership. This study contributes to the understanding of diffusion phenomena through a modelling approach with a specific focus on the role of innovativeness and opinion leadership. In our suggested model of diffusion, we propose the use of innovativeness as a filter for potential customers and an indicator to explain opinion leadership. The model is perhaps one of the few applicable tools that consider the role of opinion leadership in diffusion from a heterogeneous level. We show the model's applicability in a case of 3G mobile phone technology in Japan. The results 
demonstrate better fitting and forecasting performance of the model than the benchmarks, which means that our approach is appropriate.

Moreover, innovations usually target the most innovative customers in the initial stage, and then gradually expand to cover the majorities. Hence, we show that using innovativeness as a filter for potential customers can better fit the above fact and provide more accurate empirical results. Further, the model and the results suggest the innovative level of opinion leaders and the influential power of opinion leaders are both important factors of diffusion. Also interestingly, the model has the potential to identify and predict opinion leaders of a diffusion process. This will especially benefit firms, as they can target those most valuable customers and make appropriate strategic decision before their rivals.

This research is subject to some limitations. We developed the model based on a combination of the theories, the abstract of the facts, and the assumptions that are deduced from the existing findings, and we only validate the model using the case of a $3 \mathrm{G}$ communication technology. Therefore, for the purpose of generalization the model should be tested through more empirical cases with various settings. In addition, we used the data of income as the input of customers' innovativeness, for the sake of simplicity. It is appropriate in our case since the studied innovation is relatively more expensive than the old technologies, especially in the initial stage of release. While we do realise that this approach does not work in all innovation diffusion cases. For instance, for those innovations that are successful due to their low adoption cost (e.g. downloadable digital media to CDs and DVDs), income is not a valid factor for customers' early adoption behaviour. Hence, future studies should introduce or develop more robust measures of innovativeness in order to further validate the model and its results.

Although with limitations, we view this research as an important step for the study of diffusion models. Our model is expected to influence future studies to explore further the role of innovativeness and the nature of opinion leadership effect in diffusion. The results of this study could be enhanced and extended in a number of directions and we list some of them as following. First, the model and the case in this study is a product for individual customers, while the proposed model may also have the potential to work on the organisational level of innovation diffusions. Second, we use a modified normal distribution function to depict the relationship between innovativeness and opinion leadership, for the sake of simplicity. Fu- 
ture research should explore and test alternative functions and seek the best one. Third, this study considers the word-of-mouth effect with a specific focus on the role of opinion leadership. This can be further explored by combining other factors, such as network structure and spatial location, in order to provide a more comprehensive view of customers' interactions in diffusion. For instance, our suggested model is based on a relatively simple network structure. Given the importance of network structure on opinion leadership and diffusion (Watts and Dodds, 2007), it is of interest to further test the model with different network structures (Bohlmann et al., 2010). Last, but not least, the proposed model suggests a new perspective on how the heterogeneity of opinion leadership can influence the diffusion process. The results can be linked to studies of innovation policies in order to generate higher impact. 


\section{REFERENCES}

Amini, M., Li, H., 2011. Supply chain configuration for diffusion of new products: An integrated optimization approach. Omega 39, 313-322.

Amini, M., Wakolbinger, T., Racer, M., Nejad, M.G., 2012. Alternative supply chain production-sales policies for new product diffusion: An agent-based modeling and simulation approach. European Journal of Operational Research 216, 301-311.

Banerjee, A.V., 1992. A Simple Model of Herd Behavior. The Quarterly Journal of Economics 107, 797-817.

Bank, T.W., 2010. GDP per capita (current US\$) | Data | Table.

Bass, F.M., 1969. A New Product Growth for Model Consumer Durables. MANAGEMENT SCIENCE 15, 215-227.

Bemmaor, A.C., 1994. Modeling the diffusion of new durable goods: Word-of-mouth effect versus consumer heterogeneity, in: Laurent, G., Lilien, G.L., Pras, B. (Eds.), Research Traditions in Marketing. Kluwer, Boston, pp. 201-223.

Bemmaor, A.C., Lee, J., 2002. The Impact of Heterogeneity and Ill-Conditioning on Diffusion Model Parameter Estimates. Marketing Science 21, 209-220.

Bohlmann, J.D., Calantone, R.J., Zhao, M., 2010. The Effects of Market Network Heterogeneity on Innovation Diffusion: An Agent-Based Modeling Approach. Journal of Product Innovation Management 27, 741-760.

Chandrasekaran, D., Tellis, G.J., 2008. Global Takeoff of New Products: Culture, Wealth, or Vanishing Differences? Marketing Science 27, 844-860.

CIA, 2012. The World Factbook: Japan, https://www.cia.gov/library/publications/the-worldfactbook/geos/ja.html.

Crespell, P., Knowles, C., Hansen, E., 2006. Innovativeness in the North American Softwood Sawmilling Industry. Forest Science 52, 568-578.

Davies, S., 1979. The Diffusion of Process Innovations. Cambridge University Press, Cambridge.

Decker, R., Gnibba-Yukawa, K., 2010. Sales Forecasting in High-Technology Markets: A Utility-Based Approach. Journal of Product Innovation Management 27, 115-129.

Di Benedetto, C.A., 2011. From the Editor. Journal of Product Innovation Management 28, 146-147.

DoCoMo, 2011. IR Documents.

Emmanouilides, C.J., Davies, R.B., 2007. Modelling and estimation of social interaction effects in new product diffusion. European Journal of Operational Research 177, 1253-1274.

Flynn, L., Goldsmith, R., Eastman, J., 1996. Opinion leaders and opinion seekers: Two new measurement scales. Journal of the Academy of Marketing Science 24, 137-147.

Fourt, L.A., Woodlock, J.W., 1960. Early Prediction of Market Success for New Grocery Products. The Journal of Marketing 25, 31-38.

Geroski, P.A., 2000. Models of technology diffusion. Research Policy 29, 603-625. 
Goldenberg, J., Barak, L., Muller, E., Peres, R., 2006. Blazing Saddles: the Early and Mainstream Markets in the High-tech Product Life Cycle. Israel Economic Review 4, 85-108.

Goldenberg, J., Han, S., Lehmann, D.R., Hong, J.W., 2009. The Role of Hubs in the Adoption Process. Journal of Marketing 73, 1-13.

Goldenberg, J., Libai, B., Muller, E., 2002. Riding the Saddle: How Cross-Market Communications Can Create a Major Slump in Sales. The Journal of Marketing 66, 1-16.

Goldsmith, R., Hofacker, C., 1991. Measuring consumer innovativeness. Journal of the Academy of Marketing Science 19, 209-221.

Griliches, Z., 1957. Hybrid Corn: An Exploration in the Economics of Technological Change. Econometrica 25, 501-522.

Hall, B.H., 2005. Innovation and Diffusion, in: Fagerberg, J., Mowery, D.C., Nelson, R.R. (Eds.), The Oxford Handbook of Innovation. Oxford University Press, Oxford.

Hamilton, B.A., 1982. New Product Development in the 1980s. Booz, Allen \& Hamilton, New York.

Hauser, J.R., Tellis, G.J., Griffin, A., 2006. Research on Innovation: A Review and Agenda for Marketing Science. Marketing Science 25, 687-717.

Iyengar, R., Bulte, C.V.d., Valente, T.W., 2011. Opinion Leadership and Social Contagion in New Product Diffusion. Marketing Science 30, 195-212.

Katz, E., Lazarsfeld, P.F., 1955. Personal influence. The part played by people in the flow of mass communication. Free Press, Glencoe, IL.

Kim, m.-S., Kim, H., 2004. INNOVATION DIFFUSION OF TELECOMMUNICATIONS:: GENERAL PATTERNS, DIFFUSION CLUSTERS AND DIFFERENCES BY TECHNOLOGICAL ATTRIBUTE. International Journal of Innovation Management 8, 223241.

Kim, M.-S., Kim, H., 2007. Is there early take-off phenomenon in diffusion of IP-based telecommunications services? Omega 35, 727-739.

Kim, N., Srivastava, R.K., 2007. Modeling cross-price effects on inter-category dynamics: The case of three computing platforms. Omega 35, 290-301.

Klink, R.R., Athaide, G.A., 2010. Consumer Innovativeness and the Use of New versus Extended Brand Names for New Products*. Journal of Product Innovation Management 27, 23-32.

Lazarsfeld, P.F., Bercelson, B.R., Gaudet, H., 1940. The people's choice: How the voter makes up his mind in a presidential campaign. Duell, Sloan \& Pierce, New York.

Mahajan, V., Muller, E., Wind, Y., 2000. New-Product Diffusion Models. Kluwer Academic Press, Boston \& Dordrecht.

Mahajan, V., Peterson, R.A., 1978. Innovation Diffusion in a Dynamic Potential Adopter Population. MANAGEMENT SCIENCE 24, 1589-1597.

Mansfield, E., 1961. Technical Change and the Rate of Imitation. Econometrica 29, 741-766.

Medina, J.F., Michaels, P., 1994. Adoption of Novel Consumer Durable Goods in Less Developed Countries. Journal of Marketing Theory and Practice 2, 77-90.

Midgley, D.F., Dowling, G.R., 1978. Innovativeness: The Concept and Its Measurement. Journal of Consumer Research 4, 229. 
Midgley, D.F., Dowling, G.R., 1993. A Longitudinal Study of Product Form Innovation: The Interaction between Predispositions and Social Messages. Journal of Consumer Research 19, 611-625.

Moore, G.A., 1991. Crossing the Chasm. Harper Business, New York.

Muller, E., Yogev, G., 2006. When does the majority become a majority? Empirical analysis of the time at which main market adopters purchase the bulk of our sales. Technological Forecasting and Social Change 73, 1107-1120.

Peres, R., Muller, E., Mahajan, V., 2010. Innovation diffusion and new product growth models: A critical review and research directions. International Journal of Research in Marketing 27, 91-106.

Rand, W., Rust, R.T., 2011. Agent-based modeling in marketing: Guidelines for rigor. International Journal of Research in Marketing 28, 181-193.

Roehrich, G., 2004. Consumer innovativeness: Concepts and measurements. Journal of Business Research 57, 671-677.

Rogers, E.M., 1962. Diffusion of Innovations. Glencoe: Free Press.

Rogers, E.M., 2003. Diffusion of Innovations, 5 ed. Simon \& Schuster.

Rogers, E.M., Cartano, D.G., 1962. Methods of Measuring Opinion Leadership. The Public Opinion Quarterly 26, 435-441.

Rogers, M., 1998. The Definition and Measurement of Innovation. Melbourne Institute of Applied Economic and Social Research, pp. 1-27.

Ruvio, A., Shoham, A., 2007. Innovativeness, exploratory behavior, market mavenship, and opinion leadership: An empirical examination in the Asian context. Psychology and Marketing 24, 703-722.

Sheth, J.N., Sisodia, R.S., 1999. Revisiting Marketing's Lawlike Generalizations. Journal of the Academy of Marketing Science 27, 71-87.

Smith, K., 2005. Measuring Innovation, in: Fagerberg, J., Mowery, D.C., Nelson, R.R. (Eds.), The Oxford Handbook of Innovation. Oxford University Press, Oxford.

Summers, J.O., 1971. Generalized Change Agents and Innovativeness. Journal of Marketing Research 8, 313-316.

Tellis, G.J., Yin, E., Bell, S.J., 2009. Global Consumer Innovativeness: Cross-Country Differences and Demographic Commonalities. Journal of International Marketing 17, 1-22.

Van den Bulte, C., Joshi, Y.V., 2007. New Product Diffusion with Influentials and Imitators. Marketing Science 26, 400-421.

Van den Bulte, C., Stremersch, S., 2004. Social Contagion and Income Heterogeneity in New Product Diffusion: A Meta-Analytic Test. Marketing Science 23, 530-544.

van Eck, P.S., Jager, W., Leeflang, P.S.H., 2011. Opinion Leaders' Role in Innovation Diffusion: A Simulation Study. Journal of Product Innovation Management 28, 187-203.

Venkatesan, R., Krishnan, T.V., Kumar, V., 2004. Evolutionary Estimation of Macro-Level Diffusion Models Using Genetic Algorithms: An Alternative to Nonlinear Least Squares. Marketing Science 23, 451-464. 
Wang, C.L., Ahmed, P.K., 2004. The development and validation of the organisational innovativeness construct using confirmatory factor analysis. European Journal of Innovation Management 7, 303-313.

Watts, D.J., Dodds, P.S., 2007. Influentials, Networks, and Public Opinion Formation. Journal of Consumer Research 34, 441-458.

Weimann, G., Tustin, D.H., van Vuuren, D., Joubert, J.P.R., 2007. Looking for Opinion Leaders: Traditional vs. Modern Measures in Traditional Societies. International Journal of Public Opinion Research 19, 173-190.

Wolfe, R.A., 1994. Organizational Innovation: Review, Critique and Suggested Research Directions*. Journal of Management Studies 31, 405-431. 
Table 1: Model Performance

\begin{tabular}{|c|c|c|c|c|c|}
\hline \multirow{2}{*}{ Model } & \multicolumn{4}{|c|}{ Model Performance } & \multirow{2}{*}{ Ranking } \\
\hline & SSE & MAD & RMSE & $\mathbf{R}^{2}$ & \\
\hline Proposed Model & $2.6915 \mathrm{E}+12$ & $9.8647 \mathrm{E}+04$ & $1.4853 \mathrm{E}+05$ & 0.8422 & 1 \\
\hline Bass Model & $3.9605 \mathrm{E}+12$ & $1.4266 \mathrm{E}+05$ & $1.8017 \mathrm{E}+05$ & 0.7653 & 3 \\
\hline G/SG Model & $2.8242 \mathrm{E}+12$ & $1.0418 \mathrm{E}+05$ & $1.5215 \mathrm{E}+05$ & 0.8332 & 2 \\
\hline
\end{tabular}

Table 2: Estimated Parameter Value

\begin{tabular}{ccc}
\hline Model & Mean & Standard deviation \\
\hline & $\mathrm{p}=0.0731$ & 0.0113 \\
$\mathrm{q}=0.0997$ & 0.0389 \\
$\alpha=0.2466$ & 0.1518 \\
Proposed Model & $\beta=0.4763$ & 0.1718 \\
& $\delta=0.0679$ & 0.0081 \\
$\mathrm{M}=6.7943 \mathrm{E}+07^{*}$ & $2.0692 \mathrm{E}+06$ \\
& $\eta=0.9952$ & 0.0021 \\
\hline \multirow{3}{*}{ Bass Model } & $\mathrm{p}=0.0014$ & 0.0006 \\
& $\mathrm{q}=0.068$ & 0.0092 \\
$\mathrm{M}=5.8240 \mathrm{E}+07$ & $3.0047 \mathrm{E}+06$ \\
\hline \multirow{2}{*}{ G/SG Model } & $\alpha=38.2257$ & 6.8518 \\
& $\beta=0.3055$ & 0.07683 \\
& $\mathrm{~b}=0.0477$ & 0.0014 \\
$\mathrm{M}=5.9322 \mathrm{E}+07$ & $9.9512 \mathrm{E}+05$ \\
\hline *: This implies 1132 agents in the system( $\left(M / M_{\text {Agent }}\right)$ & \\
\hline
\end{tabular}

Table 3: Forecasting Performance

\begin{tabular}{ccccccc}
\hline Model & $\begin{array}{c}\text { MSE 1 } \\
(\text { CP = 100) }\end{array}$ & $\begin{array}{c}\text { Ranking 1 } \\
(\mathbf{C P}=\mathbf{1 0 0})\end{array}$ & $\begin{array}{c}\text { MSE 2 } \\
(\mathbf{C P}=\mathbf{7 0})\end{array}$ & $\begin{array}{c}\text { Ranking 2 } \\
(\mathrm{CP}=\mathbf{7 0})\end{array}$ & $\begin{array}{c}\text { MSE 3 } \\
\text { (CP = 40) }\end{array}$ & $\begin{array}{c}\text { Ranking 3 } \\
\text { (CP }=\mathbf{7 0})\end{array}$ \\
\hline Proposed Model & $1.3997 \mathrm{E}+010$ & $\mathbf{1}$ & $1.4922 \mathrm{E}+010$ & $\mathbf{1}$ & $3.4788 \mathrm{E}+10$ & $\mathbf{2}$ \\
Bass Model & $4.0871 \mathrm{E}+010$ & $\mathbf{3}$ & $2.7962 \mathrm{E}+010$ & $\mathbf{3}$ & $6.9717 \mathrm{E}+10$ & $\mathbf{3}$ \\
G/SG Model & $2.5067 \mathrm{E}+010$ & $\mathbf{2}$ & $1.9137 \mathrm{E}+010$ & $\mathbf{2}$ & $3.1545 \mathrm{E}+10$ & $\mathbf{1}$ \\
\hline
\end{tabular}




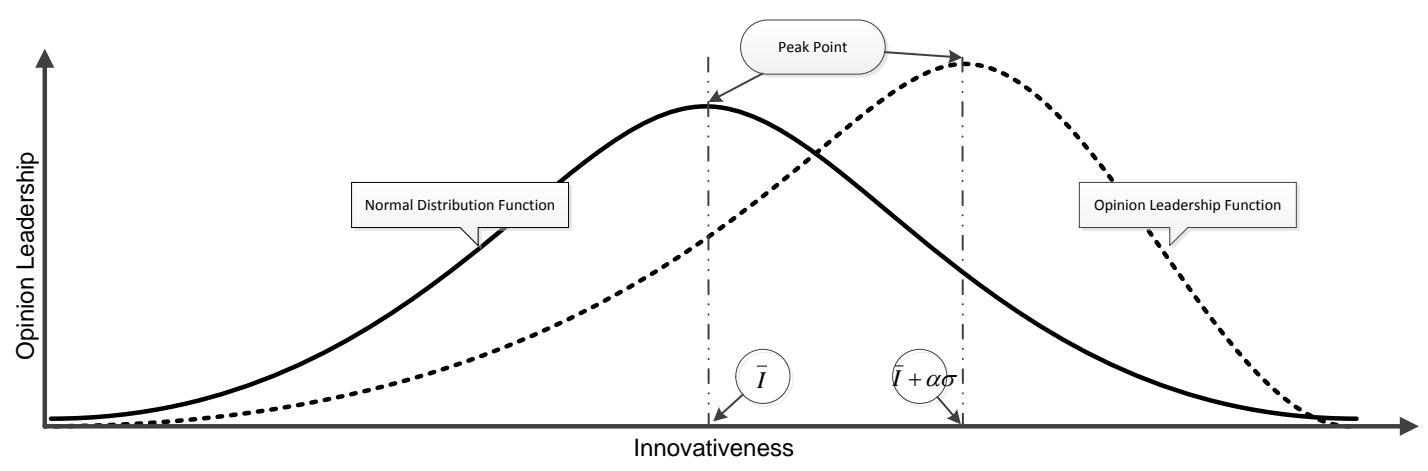

Figure 1: Opinion Leadership verse Innovativeness
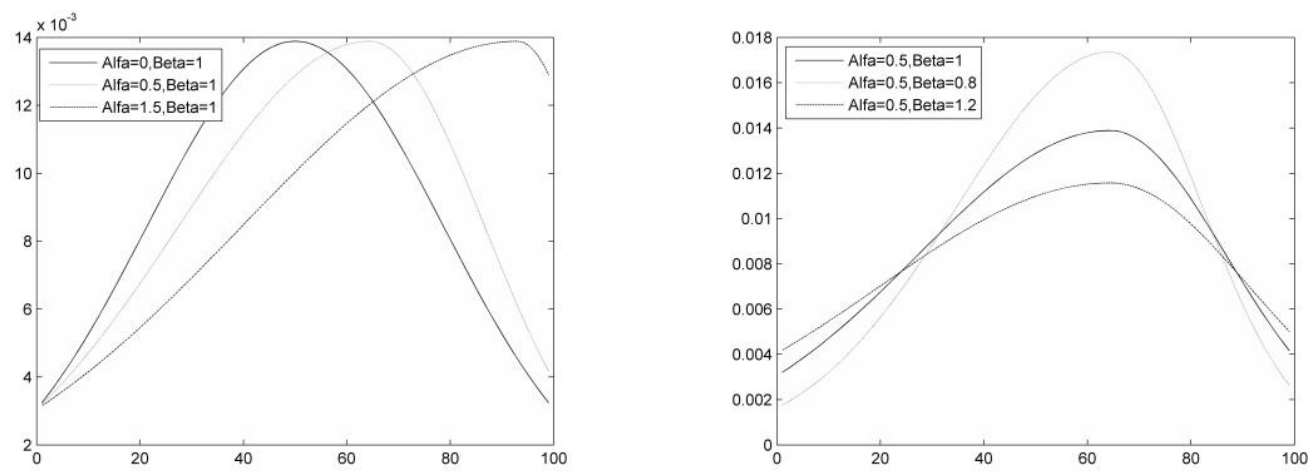

Figure 2: Function 6 - Opinion Leadership verse Innovativeness

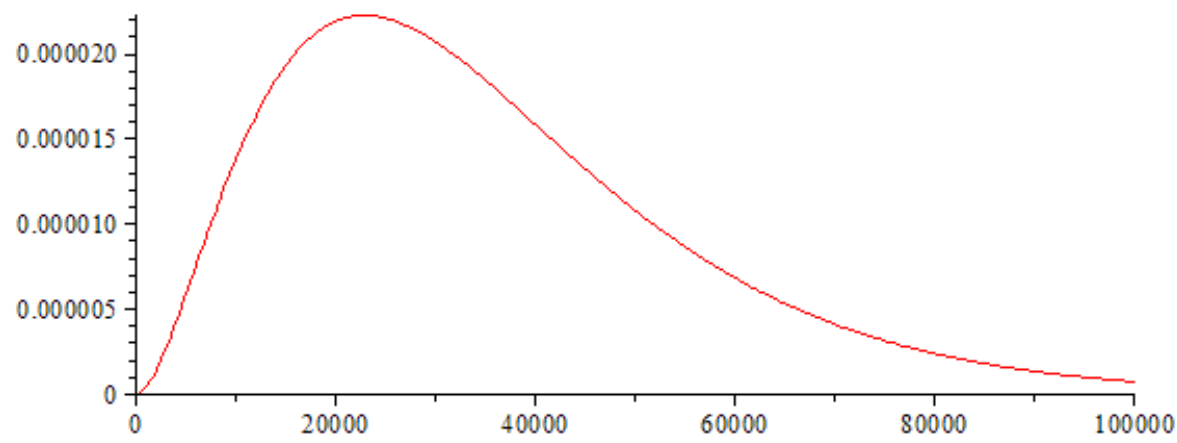

Figure 3: Income Distribution of Japan
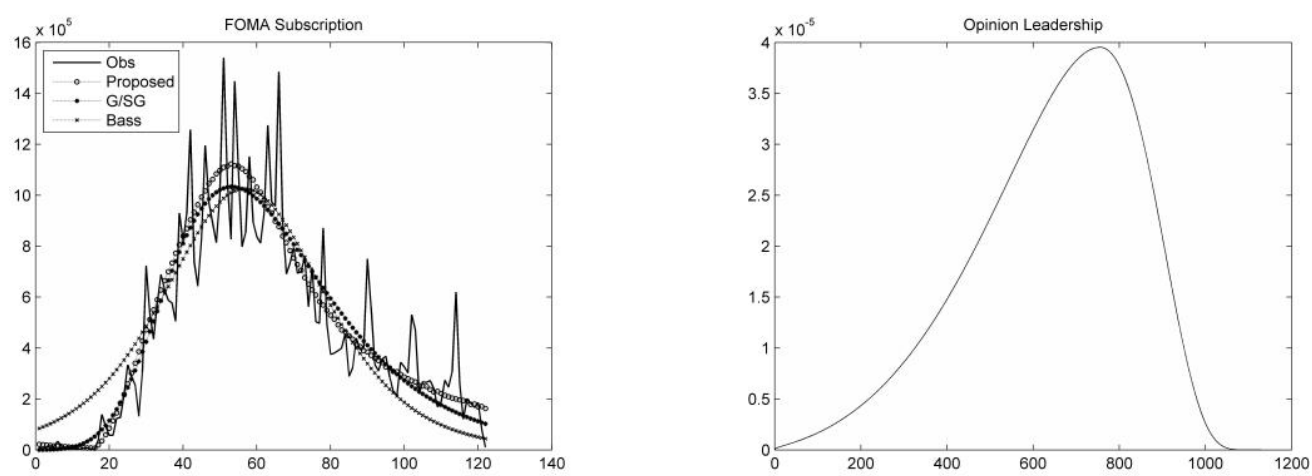

This figure shows the opinion leadership held by customers in each agent (calculated by Equation 6); $x$-coordicate lists the agents from low innovativeness to high innovativeness (1132 agents intoal, see Table 2)

Figure 4: Curve Fitting Result 

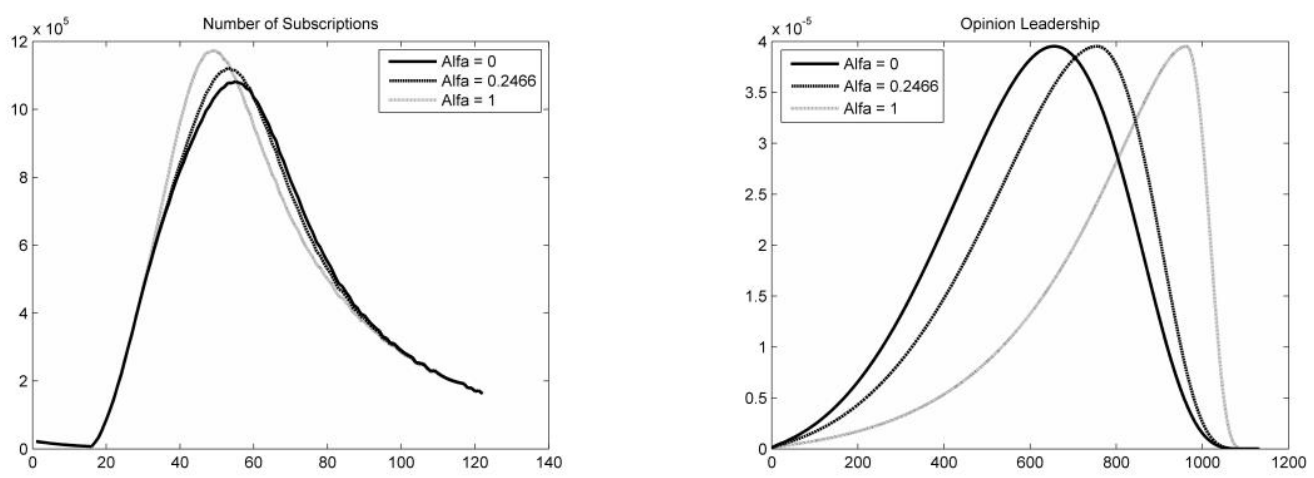

This figure shows the opinion leadership held by customers in each agent (calculated by Equation 6); x-coordicate lists the agents from low innovativeness to high innovativeness

Figure 5: Opinion Leadership: Parameter $\alpha$
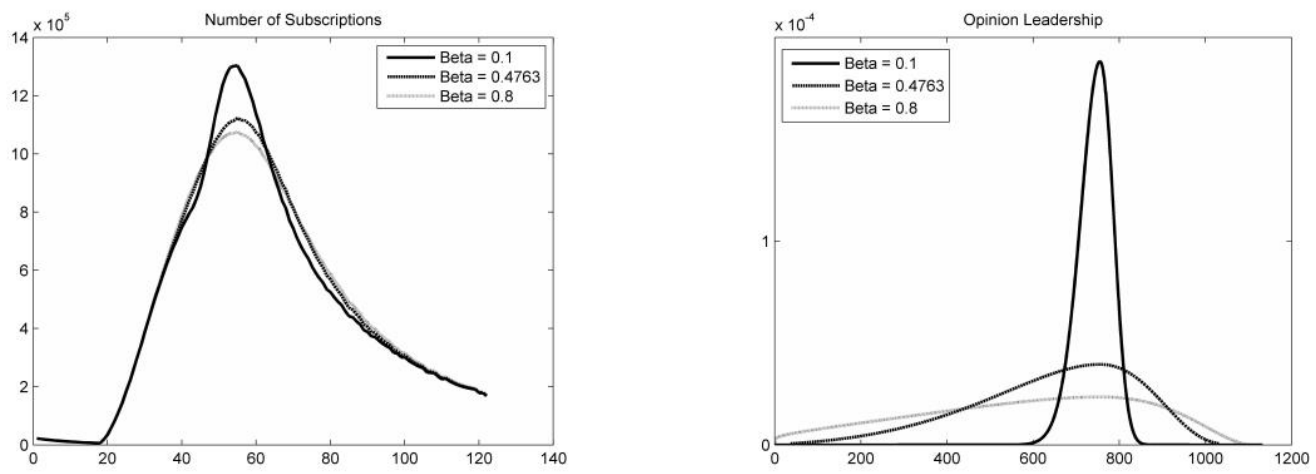

This figure shows the opinion leadership held by customers in each agent (calculated by Equation 6); x-coordicate lists the agents from low innovativeness to high innovativeness

Figure 6: Opinion Leadership: Parameter $\beta$

28 